crystal field and exchange effects. Much of this is of direct and special relevance to ferrites and the inclusion of a quite lengthy discussion of Pauli paramagnetism and of Stoner's treatment of itinerant electron ferromagnetism, though it does much to broaden the scope of the book, seems somewhat out of place. The final chapters deal, essentially, with permanent magnets, soft magnetic materials and the theory of ferromagnetic domains. The discussion of domains makes extensive use of the author's own work on magnetostatic effects. Bubble domains are not mentioned until the final paragraph. But the relevance of magnetostatic effects to bubble domains is clearly very great and the treatment of domains, at first sight both idiosyncratic and disproportionate, takes on a topical and timely aspect when viewed against the present interest in domain devices.

The book does not seem to be very suitable as a general introduction to magnetism. Topics such as antiferromagnetism, spin-waves and (surprisingly) molecular fields are scarcely mentioned. On the other hand, the author, having selected his field, has wisely refused to stray outside it. One cannot have it both ways. Within its self-imposed limitations this is a useful book.

$$
\text { E. W. LEE }
$$

\section{Layman's Cosmology}

The Nature of the Universe. By Clive Kilmister. Pp. 216. (Thames and Hudson: London, October 1971.) £2.25.

THE past few years have seen a number of new books on astronomy at the non-technical level. This is a reflexion of the rapid and remarkable development in this field during the past decade, as well as of the layman's curiosity about what goes on "up there". Professor Kilmister's book is intended to provide a stimulus to this curiosity.

The book is divided into eight chapters. The first chapter prepares the reader for the vast distances and long time scales he will encounter in cosmology and acquaints him with some of the objects of interest to the astronomer. The next two chapters are historical, showing how man's understanding of the heavens evolved from the early Greeks to the present century. The author points out the great landmark in this development: the Newtonian laws of motion and gravitation; and makes the important distinction between the descriptive theories which preceded it and the causal ones which followed it. Chapter 4 attempts (not unsuccessfully) to explain the remarkable ideas of special and general relativity. This is followed by a description of the so-called rival theories of cosmology-the big-bang and the steady state theories. The observational material relevant to these theories, or to the structure of the universe as a whole, is discussed in the next two chapters. Lest the reader should think that there are only two types of cosmological theory, the author devotes the last chapter to a brief survey of other, more esoteric theories which have come from such brilliant minds as Dirac, Eddington and others. Rightly, he leaves the discussion inconclusive, pointing out the pros and cons of the theories, the "ifs" and "buts" of the observations.

The text is easy to read and very well illustrated with diagrams and photographs, some in colour. While the rapid progress in astronomy may make some of the material of this book out of date fairly soon, the book itself should serve as a useful guide to the lay reader for many years.

\section{J. V. NARLIKAR}

\section{Hebrew Science}

Studies in Hebrew Astronomy and Mathematics. By Solomon Gandz. Pp. xii +544 (Ktav Publishing: New York, February 1970.) \$25.

THE interest of the ancient Hebrews in astronomy and mathematics arose primarily as an incidental consequence of a preoccupation with secular and religious law. A central problem was the establishment of a fixed calendar. In his very helpful introduction to this collection of essays, Professor Shlomo Sternberg of Harvard University summarizes the relevant astronomical observations: the daily rotation of the celestial sphere with the fixed stars; the annual motion of the Sun along the ecliptic as a natural explanation of the disappearance and reappearance of stellar constellations, and of the solstices and equinoxes (the Sun "walks to the south and turns to the north"); the motion of the Moon as a conveniently simple means of keeping track of the days, in spite of the irregular length of the month; and the nineteen-year cycle with seven thirteen-month and twelve twelve-month years (known to the Babylonian astronomers as far back as the fourth century $\mathrm{BC}$ ).

There seems no reason to doubt the traditional view that the fixed Hebrew calendar was enacted in the fourth century AD, but the absence of a definitive text on the calendar earlier than the eleventh-century Sefer ha-Ibbur and the relevant parts of the Maimonides Code has set many problems for students of rabbinic law and its development. Thus in one essay Dr Gandz discusses the argument in the literature as to when eyewitnesses to the appearance of the hodesh-the visible new Moon crescent-were dispensed and the new month determined by the computed molad or mean conjunction; in another he enquires at what epoch it became customary to celebrate two new Moon days (compare I Samuel, 20).

The mathematical section includes the original texts with translations of Mishnat ha-Middot, a Hebrew geometry from about $\mathrm{AD} 150$, and of a parallel Arabic geometry by alKhowarizmi. There is an essay on the development of Hebrew numerals and of gematria, calculations based on the numerical values of letters, and closer in spirit to cryptography than to mathematics; a rather unconvincing propaganda piece which overcorrects the earlier neglect of Babylonian and Hebrew mathematics and astronomy; and a study of the excursuses into mathematics of Saadia Gaon, the father of Jewish scholasticism.

The essay likely to arouse the widest interest is on "The Zodiacal Light in Ancient Hebrew Literature". Dr Gandz claims that this phenomenon-observed and noted in the sixteenth and seventeenth centuries by Kepler, Descartes, Cassini and Hooke-enables us to understand better many references in oriental literature. It is referred to variously by the Arabs as the "false dawn", the "pillar of the dawn", and the "wolf's tail". The ancient Egyptians apparently deified and worshipped this pyramid of light as the "herald and harbinger of the rising sun". (It is even proposed that it accounted for their predilection for building pyramids and obelisks!) Gandz suggests that the author of Genesis similarly had in mind the Zodiacal light when he wrote " $Y$ ' hi 'Or"-_Let there be light"--for the work of creation on the first day, deferring the creation of the Sun, Moon and stars until the fourth day. He supports this by a similar translation of the word 'Or in passages from Job, Ecclesiastes and Isaiah. Further, he is convinced that the "pillar of fire" which guided the Israelites out of Egypt by night also refers to the (miraculously magnified) Zodiacal light. In his view, the author of Exodus intends it as an "ironical allusion to the Egyptian god who manifests himself as a pillar of light": Yahweh, the creator of the luminous pyramid (along with everything else), rams home the moral to the Egyptians by employing their "god" to act on behalf of their victims.

Gandz looks forward to the discovery of some analogous meteorological reality behind the "pillar of cloud by day". He is a member of a long line of scholars who have tried to account in naturalistic terms for the phenomena to which the biblical authors allude. His ideas-whether one finds them plausible or fanciful-seem to me to be logically independent of any personal commitment to (or denial of) a theistic worldpicture.
L. Mestel 